\title{
Sensitization of Adolescents Towards Sustainable Development
}

\author{
Pramila Ramani ${ }^{1, *}$, Neela Nandan Dongre ${ }^{2}$ \\ ${ }^{1}$ Navrachana University, School of Science and Education B.Sc., B.Ed Programme Vasna Road Vadodara, 391410, Gujarat, India \\ ${ }^{2}$ Jeevan Sadhana English Medium High school, Navi Dharti, Bhutadi Zampa, Vadodara, 390001, Gujarat, India
}

\begin{abstract}
The 47th session of the UNESCO International Conference on Education in 2004 drew attention of the world to the fact that half the world's population is under the age of 25, forming the largest generation of young people ever. It is estimated that by 2020, 87 per cent of the world's young people will be living in developing countries. India will have majority of adolescents. Hence the responsibility of teachers in secondary schools increases. It asks for quality education, by which the adolescent understand their responsibility towards the environment, natural resources and sustainable development. In this direction the sensitization of adolescent towards sustainable development is essential.
\end{abstract}

Keywords Sustainable Development, Adolescent, International Conference, Sensitization

\section{Introduction}

Education is the first and foremost a human right as proclaimed in article 26 of universal Declaration of Human Rights. It is also the key to building up skills and capacities in all domains necessary to techno-economic development. [1] "Education makes man flexible, to change and adjust with the new situations." Naturalists are of the opinion that, "Education is seen from the process of adjustment to environment; it aims at enabling the individual to be in harmony with and well adapted to his surroundings."

The 47 th session of the UNESCO International Conference on Education in 2004 drew attention of the world to the fact that half the world's population is under the age of 25 , forming the largest generation of young people ever. It is estimated that by 2020, 87 per cent of the world's young people will be living in developing countries. India will have majority of adolescents. Hence the responsibility of teachers in secondary schools increases. It asks for quality education, by which the adolescent understand their responsibility towards the environment, natural resources and sustainable development. In this direction the sensitization of adolescent towards sustainable development is essential. Even though textbooks of education boards of secondary schools emphasise on protection of the environment and sustainable development the concept can be easily understood by the students though audio visual means. The term sustainable

* Corresponding author:

pramila.maths@gmail.com (Pramila Ramani)

Published online at http://journal.sapub.org/edu

Copyright (C) 2012 Scientific \& Academic Publishing. All Rights Reserved development was coined by World Commission Environment and Development (WCED) headed by Gro Harlem Brundtland, in the report our common Future, London, 1987. It is defined as development that meets the needs of the present without compromising the ability of the future generation to meet their own needs. The dictionary meaning of sustainability is the amount or degree to which the earth's resources may be exploited without deleterious effects.

\section{Education for Sustainable Development}

The UN conference on environment and development popularly known as Earth Summit (1992) in its agenda 21 gave importance to education, awareness and training. It stressed reorienting education towards sustainable development.[2] "Education is critical for promoting sustainable development and improving the capacity of people to address environment and development issues." Further to promote awareness and diverse activities, UNO has declared 2005-14 as the decade of education for sustainable development and calls for people to do whatever possible to save the planet earth. This means the journey towards sustainable development involves everyone at every stage of life from early childhood to adult life. Realising the importance of environment education in Indian context, Honourable Supreme Court of India in their historic judgement directed that from the academic year 2004-05, environment should be taught as a compulsory subject at all levels (School/College/University of education in our country in order to protect the life support system and 
promote peaceful healthy existence.

\section{Education of Adolescents}

Adolescence is characterised by rapid physical growth, social and psychological changes, sexual maturity, social and psychological changes, sexual maturity together with experimentation, development of adult cognitive processes, and transition from childhood socio-economic development to relative independence.[3] "This transition is marked by change in the child who lives in a family to adult who has to confront with the wider society. Adolescents have often been viewed as persons with problems or rebellious sprits." However the Ministry of Health and Family Welfare, 'Country Paper', 1998, in UNFPA, 2000:6 notes that wherever positive interventions and congenial environments were provided, the adolescents responded positively. They are generally keen to be recognised as productive citizens of society, their idealism inclining them towards sensitivity on issues of social justice. The Millennium Young people's Congress (MYPC) held at Honolulu, Hawaii in 1993 made education for adolescents its top priority. It was observed that, "If every young person is educated about environmental problems, human rights, tolerance, democracy and sustainable development all other problems will vanish over time." The education for sustainable development is not the same as environmental education. The environmental education has been concern with the quality of environment and less concerned with social economic and political aspect of change. However, education for sustainable development besides ecological dimension looks into economic and social issues with the ultimate objective of improving the quality of life of people living on the planet. As mentioned earlier the population of adolescents is going to supersede all other age group people, it is necessary to initiate them towards sustainable development.

\section{Review of the Related Literature}

[4] Mishra, in his study, "Analysis of the knowledge, attitude and perception regarding sustainable development among pre-service and in-service teachers at secondary level" found that pre-service as well as in-service teachers are deficient in concepts/issues like indicators of economic development, productivity, eco-technology, waste recycling, global climate change, environmental conservation, conventional agricultural practices, and biological pest control. Both among pre-service and in-service teachers, science teachers had better knowledge than arts teachers. In each dimension, male teachers had mare knowledge than female teachers and arts female teacher had the lowest level of knowledge in each dimension.

[5] Das has observed from his study on teachers perception that most of the teachers realise the importance of greenhouse effect, global warming, deforestation but have very little knowledge of interdependence of all forms of life on earth for existence. It necessitates the development of a specific curriculum.

[6] Benjamin has conducted a study on environmental values among teacher trainees at the secondary level and found that there exists a significant difference in the mean scores of environmental values among teacher-trainees at the secondary level and male and female teacher-trainees and in terms of types of institution.

\section{Rationale of the Study}

Today, people all over the world face grave environmental problems. The continuing depletion of natural resources, deforestation, extinction of many plant and animal species, rise in global temperature, environmental pollution, depletion of life saving ozone layer, etc. are some of the few examples. These problems are further being compounded with population explosion, food crisis, hunger, malnutrition, poverty, insanitation and unbridled consumerism which together have caused serious effect on the essential life-support system of our planet.[7] "Threats to peace and security of nations from environmental breakdown are today greater than any other foreseeable military threat from conventional arms." Rousseau reacted against man's destructive nature to spoil things gifted by nature. Our environment has visibly, seriously, irreversibly changed for the worse in our life time, and it is we who are the victims. The objective of sustainable development is to provide the well-being of the present and the future generations and to maintain a healthy environment and life-support system. The World Watch Institute (WWI) in its annual publication State of the World 2006 specially focuses on the dramatic rise of the two Asian nations India and China) with about 40 per cent of world population.[8] "By 2025, India will be the only nation that is going to have the highest youth population in the world." Hence, it is the right time to plan and execute certain important measures in order to keep the young generation, a healthy one. For which it is essential to sensitise the adolescents who are very receptive and have cognitive abilities to realise the seriousness of non sustainable development. Today's adolescent is tomorrow's policy maker and in the democratic nation like India even the voter needs to be well aware about sustainable development hence the presenters sensitised the adolescents.

\section{Methodology of the Study}

\subsection{Objective of the Study}

To sensitise secondary school students towards sustainable development.

\subsection{Hypothesis of the Study}

There is no significant difference in the mean scores of understanding the sustainable development before and after the treatment. 


\subsection{Design of the Study}

The study adopts the pre-test treatment post-test single group experimental design.

\subsection{Population of the Study}

There are 61 grant-in-aid schools in the city of Vadodara, functioning under the Gujarat State Board of secondary and Higher Secondary Education following the rules and regulations laid by the Ministry of Human Resources of the Government of India. The population of the study consists of all the Standard IX English medium students of Grant-In-Aid Schools of Vadodara city in the year 2010.

\subsection{Sample of the Study}

The investigators chose purposive sampling technique. 40 students of Jeevan Sadhana English Medium High School of standard IX were selected as sample for the present study.[9] Sample size of greater than 30 is considered as large size sample by central limit theorem. Our sample consisted of 40 students therefore it is an ideal sample size. Our study is single group pre test post test design therefore; same students (whole class) remained present throughout the study.

\subsection{Research Tools}

The present study used criterion reference test for understanding of sustainable development as tool. The following methods were adopted in giving marks to the students in PRE TEST and POST TEST.

Pre Test and Post Test contained parallel and equal number of questions and similar scoring patterns was adopted (as explained below).

There were 15 objective type questions with three options yes, no and not decided. If question is for sustainable development then "YES" carry 2 marks, "NOT DECIDED" carry 1 mark and "NO" carry 0 marks. If the question is against the sustainable development then "NO" carries 2 marks, "NOT DECIDED" carry 1 mark and "Yes" carries 0 marks. Students can score a maximum of thirty marks in objective type questions. Only one descriptive type question was asked which carried maximum of 10 marks, if the answer was in the direction of sustainable development. A student can score maximum of 40 marks in these tests. Total Marks were obtained out of 40 and percentage was computed for each student in pre and post test, thus the data was collected.

\subsection{Plan and Procedure of Data Collection}

Step 1: The ninth standard students of Jeevan Sadhana English Medium High School were selected purposively.

Step 2: Pre test score was collected using criterion reference test for understanding of sustainable development

Step 3: Sensitisation programme was conducted. It was composed of showing of Power Point Presentation related to non-sustainable and sustainable development followed by rigorous probing and proactive interaction. .
Step 4: Post test score was collected using criterion reference test for understanding of sustainable development.

Pre test was taken on $27^{\text {th }}$ January 2012 at $08: 30$ hours. The investigators showed power point presentation to the students along with rigorous probing for two hours. At the end of the same day at 13:00 hours the post test was taken.

\section{Objectives of the Sensitization Programme}

a. To sensitize students about air pollution.

b. To make them understand about importance of planting trees and taking care of them.

c. To make them understand about impact of deforestation and their consequences on soil, animal, humans, etc.

d. To make understand about the cause of acid rain and its impact on humans, plants, animals, buildings etc.

e. To sensitize students about industrial pollution.

f. To make them understand about the impact of urbanization.

g. To make them understand about problems of density of population.

h. To make them understand about problems of over population.

i. To make them understand about demographic transition.

j. To sensitize students about child labour.

$\mathrm{k}$. To make them understand about the depletion of fresh water, food and agricultural land.

1. To make them understand about the hazardous effects of plastic bags.

\section{Sustainable development programme}

a. Students are shown power point presentation along with rigorous probing.

b. Followed by discussion in small groups and with whole class about sustainable development.

c. Students shared their real life experiences with investigators and vice versa.

d. Related movies, TV shows, etc were discussed.

\section{Data Analysis}

The collected data was statistically treated in the following ways:

i) Mean and Standard deviation

ii) Correlated t-test

\section{Definition of used statistical indicators}

Correlated $t$ test was used with appropriate degrees of freedom and at 0.01 level of significance. Correlated $t$ test is an inferential statistics therefore whatever result we get; it can be projected to population. Correlated t test was used because our design was single group pre test-post test which is appropriate statistics for this type.

[10] A correlated-groups $t$-Test, or more generally a within-subjects design, is preferred over the independent groups t-Test (between-subjects designs), whenever it is practical to use. The preference is based on the fact that the correlated-group t-Test and all other inferential tests designed to analyze within-subjects designs, is more statistically powerful then the independent-groups t-Test and 
all inferential tests that are designed to analyze between-subjects designs. What this 'power issue' refers to is that you are more likely to produce a statistically significant result and reject your null hypothesis with a correlated-groups t-Test (within-subject analyses) than with an independent-groups t-Test (between-subjects analyses). The reason for this additional power is not based on the mean difference between conditions/samples; rather, it is based on the standard error term in the t-Test (the denominator). If you were to take any set of data that includes two conditions or levels of an independent variable, holding everything constant the mean difference between those two conditions will be the same regardless of whether you use an independent-groups t-Test or a correlated-groups t-Test. This is because you will have exactly the same values in each condition; hence, the means for each condition will be the same. However, no matter what, the error term will always be smaller for a correlated-groups t-Test than for an independent-groups t-Test. This is what makes the correlated-groups t-Test (and all within-subject design analyses) more statistically powerful. Because it has a smaller error term, the obtained t-Value will always be larger.

\section{Paired $t$ test results \\ $P$ value and statistical significance:}

The two-tailed $\mathrm{P}$ value is less than 0.0001

By conventional criteria; this difference is considered to be

extremely statistically significant.

\section{Confidence interval:}

The mean of Group One minus Group Two equals -9.08

$95 \%$ confidence interval of this difference: From -10.98 to

$-7.17$

$$
\begin{aligned}
& \text { Intermediate values used in calculations: } \\
& t=9.6251 \\
& d f=39 \\
& \text { standard error of difference }=0.943
\end{aligned}
$$

Table 1. Data Table

\begin{tabular}{|ccc|}
\hline Group & Pre Test & Post Test \\
\hline Mean & 66.70 & 75.78 \\
\hline SD & 8.47 & 7.47 \\
\hline SEM & 1.34 & 1.18 \\
\hline $\mathrm{N}$ & 40 & 40 \\
\hline
\end{tabular}

\section{Result and Discussion}

In the present study, the investigators used descriptive and inferential statistics to compare the mean scores of pre test and post test.

For 39 degree of freedom the expected t-value at 0.01 level is 2.704

Above table exhibits that the calculated value of $t$ is much greater than the expected t-value at .01 level of significance. Hence the null hypothesis is rejected at .01 level of significance. This implies that there is a significant difference between the mean scores of the students on pre test and post test, in favour of the post test.

The socio-economic condition of the secondary school students studying in the grant-in-aid schools in the city of Vadodara is more or less similar. The learning opportunities and exposure to awareness programmes are few. In this perspective the above investigation is significant for the population under study.

Table 2. Shows the significant difference in the mean scores of understanding of sustainable development among the class IX students

\begin{tabular}{|c|c|c|c|c|c|c|}
\hline Sr.No & Test & N & Mean & S.D. & $\begin{array}{c}\text { r-coefficient of } \\
\text { Correlation }\end{array}$ & t-Value \\
\hline 1 & $\begin{array}{c}\text { Pre- } \\
\text { Test }\end{array}$ & 40 & 66.70 & 8.47 & 0.73 & 9.6251 \\
\cline { 1 - 4 } 2 & $\begin{array}{c}\text { Post- } \\
\text { Test }\end{array}$ & 40 & 75.78 & 7.47 & & \\
\hline
\end{tabular}

\section{Major Findings of the Study}

1. There is a significant difference between the mean scores of the students on pre test and post test, in favour of the post test.

2. By qualitatively analysing the suggestion given by the students the sensitisation programme was found to be useful in making them understand the concept of sustainable development.

\section{Educational Implication}

1) Understanding of the concept of sustainable development plays a vital role in preserving nature.

2) By initiating the idea of sustainable development to adolescents a good relationship can be established between the future citizens and nature.

3) The concept of sustainable development enriches one's knowledge of balance of nature.

4) The knowledge of sustainable development will help the adolescents to think on 'Reduce, Recycle and Renew'.

5 ) The concept of sustainable development is essential in order to save the lives of the present and future generations.

\section{Conclusions}

The students have an average level of knowledge of the concept of sustainable development.[11] "NPE (1986 and as amended in 1992) has mentioned the importance of environment education, "there is a paramount need to create a consciousness of the environment. It must permeate all ages and all sections of society, beginning with the child. Environmental consciousness should inform teaching in schools and colleges. This aspect will be integrated in the entire educational process." But teaching the adolescents about environment alone is not sufficient. Realizing the increase in magnitude of human impact on the environment 
and the consequent deterioration of the latter, the chairman of World Commission on Environment and Development (WCED) Dr. Brundtland reiterated to understand the importance of sustainable development in the report in 1987. This study suggests that the understanding the concept of sustainable development is essential in order to save the lives of the present and future generations.

\section{REFERENCES}

[1] Chaube, K. (2002). Environmental Development. Centre for Scientific Research, pp.75- 76.

[2] Satapathy, M.K. (2007). Education Environment and sustainable development. Delhi Shipra Publications.

[3] Saldanha, D. (2007). Education of adolescents for development in India. Jaipur: Rawat Publications.

[4] Mishra, B.P. (2002), Analysis of the knowledge, attitude and perception regarding sustainable development among pre-service and in-service teachers at secondary level. $\mathrm{Ph}$. D. Thesis, Utkal University, Bhubaneswar, Orissa, p.231.

[5] Das, P. (2003), Study of teacher's perceptions of curricular and pedagogical issues underlying education for sustainable development. Academic Report, Regional Institute of Education, Bhubaneswar, p.35.

[6] Benjamin, E.W. (2009). A Study on Environmental Values among Teacher Trainees at the Secondary Level. New Frontiers in Education ISSN: 0972-1231 Vol.42, No.4, October-December.

[7] Rao, P. N. (1999), Protection of environment and basic needs of mankind. Environment and people 6(4):5-12.

[8] Saldanha, D. (2007). Education of adolescents for development in India. Jaipur: Rawat Publications.

[9] http://stattrek.com/sampling/sampling-distribution.aspx date 07.09.2012

[10] https://sites.google.com/site/fundamentalstatistics/chapter-18 date 07.09 .2012

[11] Chowdhry, N.K. (2009). Indian Constitution and Education. Delhi: Shipra publications. 